\title{
DETERMINANTS OF PASSENGERS' CHOICE: A CASE STUDY OF MALLAM AMINU KANO INTERNATIONAL AIRPORT (NIGERIA)
}

\author{
Andrew Egba Ubogu ${ }^{1}$ \\ ${ }^{1}$ Department of Geography, Amadu Bello University, Zaria, Nigeria
}

Received 11 October 2012; accepted 25 January 2013

\begin{abstract}
Airports vary in their ability to attract traffic especially when such airports have competitors for air traffic. This study examines choice factors that air travelers consider most as determinants of their choice for an airport. The study relied on primary data obtained through the administration of questionnaire survey. The survey was conducted in Mallam Aminu Kano International Airport, Kano where air passengers were sampled purposively as they await to board their international flights at the international airport. In all, 240 respondents were interviewed. The technique of data analysis employed include correlation matrix and factor analysis. The results of the correlation matrix obtained indicate that the choice factors considered are positively correlated. The factor loadings indicate that of all the variables considered in the study, the location of the airport in the region, access time to airport, frequency of flight at the airport are the three most significant factors that air passengers consider most in their choice of Kano airport. Similarly, the relationship between the choice variables that showed high positive correlations include location of the airport in the region and access time to the airport $(r=0.97)$, previous usage of the airport and minimum waiting time $(r=0.98)$ as well as available parking space at the airport and low fare charges $(r=0.92)$. The implications of this result are paramount for airport planning and management especially for airports attracting traffic in multi-airport regions.
\end{abstract}

Keywords: multi-airports, traffic, terminal, airport choice, passengers.

\section{Introduction}

The literature is inundated with several studies that have tended to examine the ability of an airport to attract passengers more than its competitors. Such studies include the works of Caves (1996), Oum and Park (2004) and Lian and Ronnevik (2011). Airports are spatial features that compete in such a way that resources tend to cluster in the most lucrative airports. Factors often considered by prospective users which determine the competitiveness of airports include improved road infrastructure to the airport as well as lower air fares. As Gjerdaker et al. (2008) observed, this phenomenon has contributed to higher levels of traffic leakage from a regional airport to a nearby main airport in Norway. Incidentally, airport traffic leakage occurs when travelers avoid using the local airport in their region and use other airports in order to take advantage of lower fares and better airline services (Fuellhart, 2007).

Indeed, many factors influence an airport's ability to attract traffic. These factors include the airports' current traffic flow patterns, airport's infrastructure capacity and activities,

\footnotetext{
${ }^{1}$ Corresponding author: aeubogu@abu.edu.ng
} 
linkage with regional or intercontinental network, service quality, as well as airport cost factor (Ohashi et al., 2005; Oum and Park, 2004; Caves, 1996). Some authors have equally observed that airport choice in a multi-airport region could depend on factors such as airport access time, flight frequency, differences in air fares, the purpose of travel as well as the type of airline (Ishii et al., 2009; Hess and Polak, 2005; Basar and Bhat, 2004).

Kanafani and Young (1977) investigated the choice of an airport in a multi-airport metropolitan area. They indicated that flight frequency and ground accessibility plays critical role in determining the traffic that an airport attracts. Harvey (1987) also observed that access time and flight frequency are statistically significant in determining airport choice, although, those traveling for leisure purposes have a lower valuation of time. Expanding the variables further, Thompson and Caves (1993) found that leisure travelers access time to the airport, air fare and the maximum number of seats available are statistically significant in explaining airport choice in the south of England. Air travelers have similarly been found to likely select an airport they have chosen in the past (Windle and Dresner, 1995).

It is apparent that some of these studies (Harvey, 1987; Ashford and Bencheman, 1987) have relied on disaggregated behavioural choice models which is estimated with a dependent variable representing a single occurrence, observation or passenger. The model treats demand as a micro-context specifying the consumption and or choice patterns and the behaviour of each individual air traveler (Ozoka, 2009). Of the three most common behavioural models namely discriminant, probit and logit models, the logit model in the form of Multinomial Logit Model (MNL) has been the most successfully applied in airport choice. Pels et al. (2003) adopted a Nested Logit (NL) model to explain airline and airport competition for passenger's departure choice in San Francisco Bay Area using fares and flight frequency to explain the first choice and airport tax to determine the latter.

Similarly, the works of Basar and Bhat (2004) and Hess and Polak (2006) adopted MNL and NL in a modified form called the Cross Nested Logit (CNL) model respectively in the study of greater London area. Access time was identified to be a determining factor in air traveler's choice of departure airport. Furthermore, flight frequency, access cost and flight time also played important role in airport choice, although, air fares were not found to have played a significant role in the choice of airport by travelers (Hess and Polak, 2006). A careful examination of these studies reveals that access time and flight frequency are commonly found to be key factors in explaining choice although their relevance varies with different segmentation strategies. Evidence also abounds to show that passengers' behaviour varies for homogenous though separate groups; for example, business or leisure travelers that are probably within the same group.

Incidentally, while most of these studies were undertaken in countries and regions with well developed air transport system, few studies exist in developing countries like Nigeria where the air transport industry is growing faster than that of the world. In recent years, air traffic has been on the increase in Nigeria with the increase attributed to government's rigorous provision of navigational aid facilities, basic aeronautical equipments and high level of security at the nations' airports (NCAA, 2003). However, in spite of the general increase in air transport system, there seem to be an uneven distribution within the country's airport. 
Whereas some airports experience low utilization with consequent inability to maximize profits, others experience high utilization. Airport characteristics and developments are influenced both by market and regulatory forces especially in multi-airport regions where each airport actively competes for passengers. In this setting, passengers have various choices of routes and airport of departure. Indeed, since a specific point of departure is important, such airports are over time selected for their international flights. Generally speaking, while several existing studies provide exploratory discussions of the determinants of airport choice in developed countries with well developed air transport industry, not many studies on airport choice exist in Nigeria. In fact, where such studies are found, they lack in-depth empirical analysis needed for airport planning in a multi-airport country like Nigeria.

In the civil aviation industry, travel demand fluctuations results in capacity constraints which become obvious in terms of over investment or under investment in facilities. These in turn gives rise to under-utilization or over-utilization of the facilities, and so affects the efficient use of the transport system and revenue (Ozoka, 2009). The implication of this is that given a choice amongst competing options or airports, travelers will be expected to choose that option or airport which they perceive to have the maximum attribute.

The fundamental purpose of this paper is to determine the factors that international air travelers at the Mallam Aminu Kano International Airport, Kano, consider most in determining their choice of airport of departure. This is with a view to investigating why passengers choose the airport for their international flight departure at the detriment of other airports in Nigeria.

\section{Methodology}

The data sets for this study were obtained through the use of questionnaire survey on sampled respondents at Mallam Aminu Kano International Airport (MAKIA) between the months of June and July, 2011. The respondents that were administered with the questionnaire were purposively sampled to ensure that they were about to board international flights at the airport. This was meant to ensure that the information obtained reflects the choice behaviour of international passengers at the airport. Thereafter, the passengers encountered that were willing to be surveyed were then administered with the questionnaire. Two reasons accounted for this method adopted. Firstly, the mobility of the passengers at the airport terminal implies that such passengers barely have a very short time available to attend to rigorous interview. This is because the period between the collection of boarding pass and actual boarding of the plane is short. Secondly, the airport terminal is a highly restricted area to conduct rigorous interview. However, these constraints were circumvented by employing the assistance of airport officials in administration of the questionnaire.

The survey questionnaire administered is designed based on multiple-item measurement scales fashioned on the 5-point Likert-type scale. The choice factors measured are based on ten (10) widely reported airport choice measurement items (Ozoka, 2009; Ohashi et al., 2005; Oum and Park, 2004). The variables measured include availability of aircraft flying the route, comparable low fare charges of airlines operating at the airport, average access time to the airport, passengers' previous usage of the airport and the location of the airport in the region. Other variables include the average minimum waiting time at the airport, the 
frequency of flight schedules at the airport, the connective capacity of flights from the airport, available car parking space at the airport and the nature of airport services available at the airport.

In order to evaluate the reliability of the test, internal consistency checks were conducted using Cronbach's Alpha on standardized items. Cronbach's Alpha according to Malhotra et al. (1996) is the average of all possible split-half coefficients resulting from different ways of splitting the scale items. A value of 0.6 or below indicates unsatisfactory consistency reliability. Any value above 0.6 indicates satisfactory consistency reliability. The result shows that the internal consistency of each measure is 0.91 which implies a good level of reliability (Table 1).
Table 1

Reliability Test Statistics

\begin{tabular}{lll}
\hline Cronbach's Alpha & $\begin{array}{l}\text { Cronbach's } \\
\text { Alpha Based on } \\
\text { Standardized Items }\end{array}$ & $\begin{array}{l}\text { No of } \\
\text { Items }\end{array}$ \\
0.913 & 0.912 & 10
\end{tabular}

Source: Author's computation

The statistical technique employed in the analysis of data is factor analysis. This is an attempt to explain the set of variables in terms of smaller number of dimensions out of the total number of variables analyzed. Essentially, it is designed to assess whether the covariances between the set of observed variables can be explained in terms of smaller number of common factors sometimes called latent variables. Mathematically, the factor analysis model can be written as follows:

$$
\begin{gathered}
\chi_{1}=\lambda_{11} f_{1}+\lambda_{12} f_{2} \ldots+\lambda_{1 k} f_{k}+u_{1} \\
\chi_{2}=\lambda_{21} f_{1}+\lambda_{22} f_{2} \ldots+\lambda_{2 k} f_{k}+u_{2} \\
\cdot \\
\chi \\
\chi \\
\cdot
\end{gathered}
$$

The equations above can be re-written as:

$$
\chi=\Lambda f+u \text {, }
$$

Where,

$$
\chi=\left[\begin{array}{l}
x_{1} \\
\cdot \\
\cdot \\
x q
\end{array}\right], \Lambda=\left[\begin{array}{l}
x u \ldots \lambda_{1 k} \\
\cdot \\
\cdot \\
\lambda q_{1} \ldots \lambda q k
\end{array}\right], f=\left[\begin{array}{l}
f_{1} \\
\cdot \\
\cdot \\
f k
\end{array}\right], u=\left[\begin{array}{l}
u_{1} \\
\cdot \\
\cdot \\
u q
\end{array}\right]
$$

Furthermore, since the factors are unobserved, their location and scale can be fixed arbitrarily, therefore we can assume that only part of the variation in a given population is contained 
within the variables used to define that population. For this reason, only some of the observed variations in choice factors in the study area are due to variations in all the variables under consideration.

The study area is Kano city located at latitude $11^{\circ} 58^{\prime} \mathrm{N}$ and longitude $8^{\circ} 21^{\prime} \mathrm{E}$. It is the capital city of Kano State. The city of Kano is located on the high plains of northern Nigeria and is about $440 \mathrm{~km}$ from Abuja, the Nigerian capital city. The Mallam Aminu Kano International Airport (MAKIA) is the oldest airport in Nigeria and was established in 1936. MAKIA is named after a renowned Nigerian politician Mallam Aminu Kano. The airport is a major airport serving the whole of northern region especially for international trips alongside the international airport in Abuja (Fig. 1). The airport operates both domestic and

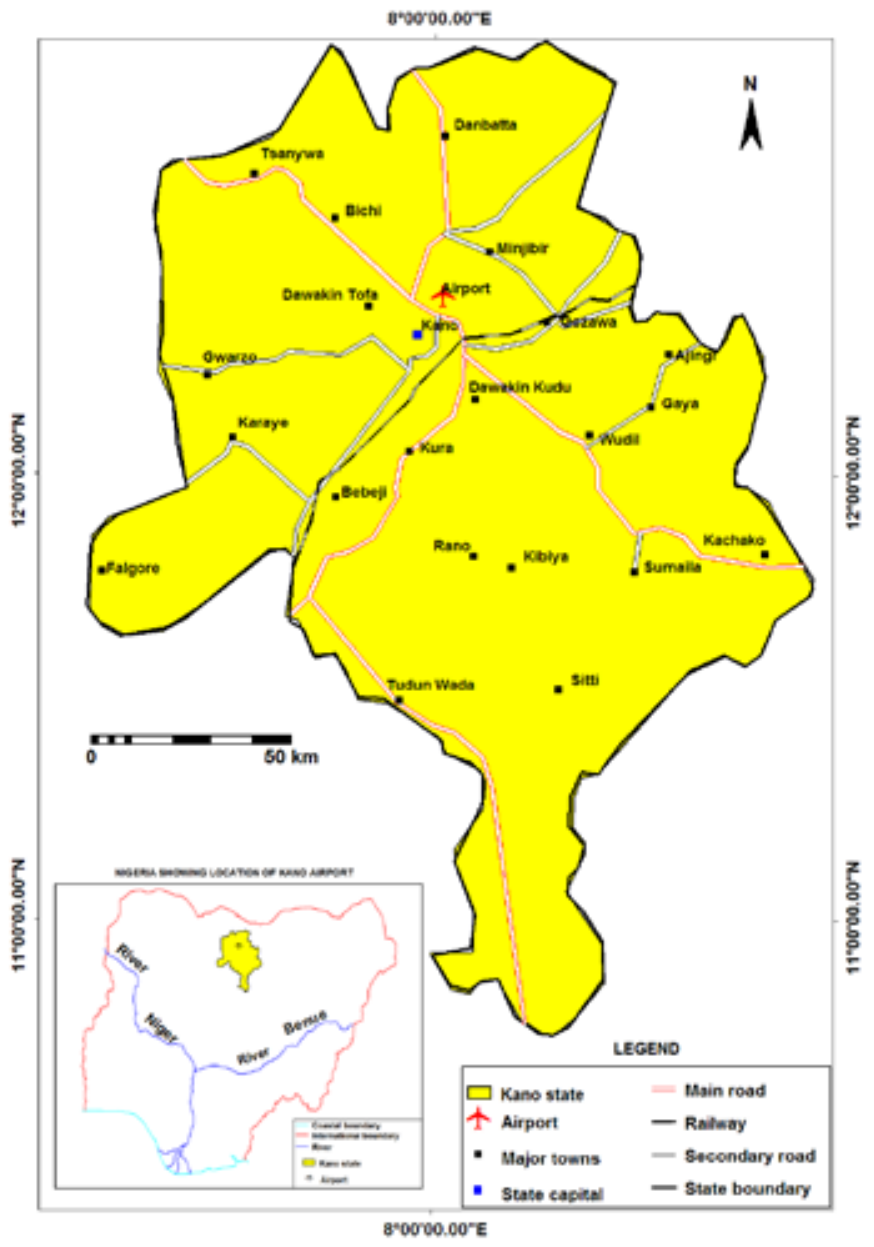

Fig. 1.

Location of Kano Airport

Source: Adapted and modified from Kano state map 
international flights accounting for an estimated $12 \%$ of all the total annual schedule international flights in Nigeria (NAMA, 2010).

\section{Results and Discussion}

Airports as spatial nodes compete among themselves for passengers especially in multiairport country like Nigeria. Some studies (Park et al., 2004; Ohashi et al., 2005) have detailed out airport service quality on passengers' choice and air cargo transshipment choice respectively in other countries. Nevertheless, the ability of an airport to attract passengers who have alternative nodes to satisfy their trip purpose needs to be extensively studied in today's air traveling business. In the face of various passengers' airport choice variables, there is the need to reduce these variables to few orthogonal variables which could be used to explain the prime factors that determine passenger's preference, use, and adoption of an airport rather than an alternative competing airport.

Table 2

Communalities of the Airport Choice Factors

\begin{tabular}{lcc}
\hline Choice Factors & Initial & Extraction \\
Availability of aircraft & 0.424 & 0.427 \\
Low fare Charges & 0.345 & 0.567 \\
Access time to the airport & 0.964 & 0.830 \\
Previous usage of the airport & 0.977 & 0.927 \\
Location of the airport in the region & 0.963 & 0.844 \\
Minimum waiting time at airport & 0.975 & 0.938 \\
Frequency of flight at the airport & 0.627 & 0.634 \\
Connective capacity of flights from the airport & 0.419 & 0.473 \\
Available parking space at the airport & 0.586 & 0.684 \\
The nature of airport services available & 0.553 & 0.632 \\
\hline
\end{tabular}

Extraction Method: Principal Axis Factoring

Source: Author's computation

jitte 235
The results of the analysis (Table 2) indicates that the estimates of the communality before and after extraction of the variables when factor-analyzed reveals that not much of the variance of the variable items 'availability of aircraft' (42.7\%) and 'connective capacity of flights from the airports' (47.3\%) can be attributed to the three common factors in the communalities table. However, variables like minimum waiting time at the airport, familiarity and previous usage of the airport, location of the airport in the region showed a variance of $93.8 \%, 92.7 \%$ and $84.4 \%$ respectively. This high percentage variance suggests that the variables can be attributed to the three common factors.

Furthermore, the variances of the extracted factors are shown in Table 3. An examination of Table 3 indicates that the percentage of the total variance accounted for by the factor analysis shows two factors with eigenvalues greater than 1 . The total variance explained indicates that factor one showed an eigenvalue 
of 5.817 accounting for $58.17 \%$ of the total variance explained by the analysis. Similarly, factor two reveals an eigenvalue of 1.293 thereby accounting for $12.93 \%$. The significance of these factor loadings provides a clear indication of the underlining dimensions of the choice factors that have been reduced to two major factors with eigenvalues greater than 1.00. These are the dominant loadings for each factor. These eigenvalues are the proportion of the total variation in the data set that is explained or at best summarized by a factor.

The cumulative percentage of variance reveals that the two factors alone accounts for $71.09 \%$. In other words, this is the proportion of the total variation that is explained by these two factors alone. Interestingly, the third factor accounts for very small proportion of the total variation of the explained variables. In order to identify the manner in which this unexplained variation is distributed among the variables, a scree plot is employed to depict the loadings as shown in Fig. 2. This plot demonstrates the distribution of the variance among the factors graphically. The 'elbow' shape of the curve indicates that higher order factors contribute a decreasing amount of additional variance with a marked decrease in the second and third factor. This implies that the choice factors under consideration can be summarized by the first two or three factors.

According to Landau and Everitt (2004) attempt must be made to identify the variables that can be used to explain the underlining dimensions of the issue under consideration. However, the communality table alone cannot be relied upon to identify the factors that explain the choice of the airport by passengers, therefore, some method of factor rotation (varimax) is employed. The purpose is to maximize the variance of the squared loadings to produce orthogonal factors with a view to interpreting the factor analysis. In practice, an arbitrary threshold value of 0.4 is equated as high loadings so that the factor loadings are reordered according to size. Furthermore, variables that load on factors 1 and 2 are

Table 3

Total Variance of the Choice Factors Explained

\begin{tabular}{lllllll}
\hline Factor & \multicolumn{2}{l}{ Initial Eigenvalues } & & \multicolumn{3}{c}{ Extraction Sums of Squared Loadings } \\
& Total & \% of Variance & Cumulative \% & Total & \% of Variance & Cumulative \% \\
1 & 5.817 & 58.173 & 58.173 & 5.577 & 55.772 & 55.772 \\
2 & 1.293 & 12.925 & 71.098 & 0.856 & 8.562 & 64.334 \\
3 & 0.885 & 8.852 & 79.950 & 0.522 & 5.218 & 69.552 \\
4 & 0.536 & 5.356 & 85.306 & & \\
5 & 0.458 & 4.584 & 89.890 & & \\
6 & 0.357 & 3.572 & 93.462 & & \\
7 & 0.336 & 3.357 & 96.818 & & \\
8 & 0.274 & 2.745 & 99.563 & & \\
9 & 0.034 & 0.343 & 99.906 & & \\
10 & 0.009 & 0.094 & 100.000 & & \\
\hline
\end{tabular}

Extraction Method: Principal Axis Factoring

Source: Author's computation 


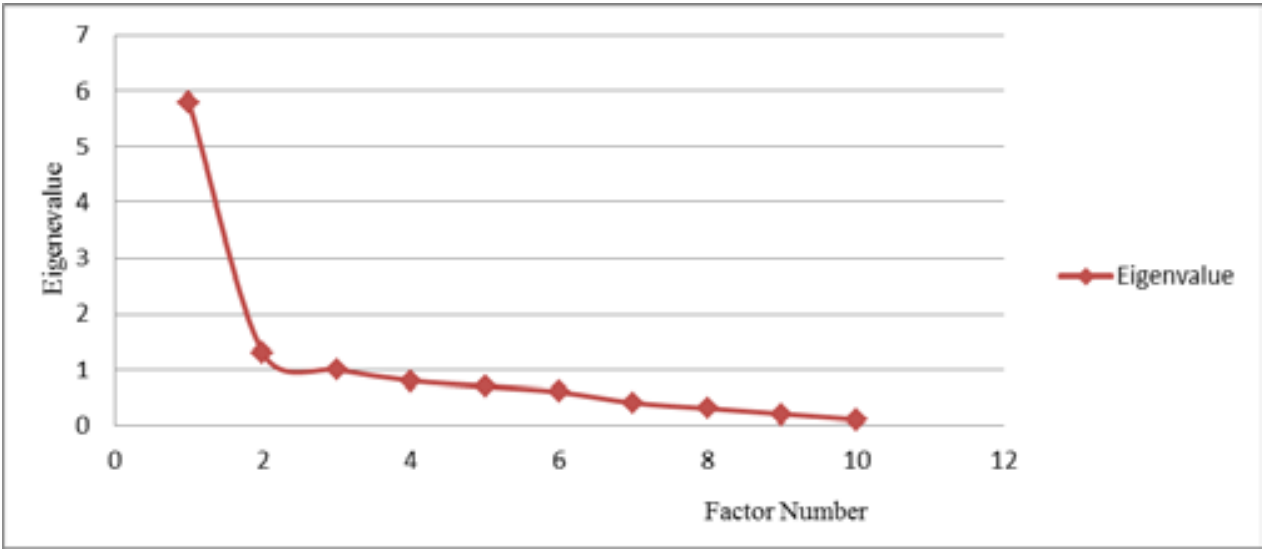

Fig. 2.

Distribution of the Factor Loadings

considered important explanatory variables. Table 4 shows the rotated factor matrix. A careful examination of Table 4 shows that some variables load on several factors. For instance, the location of the airport appears to be affected by factors 1 and 2 . This is the most important factor that explains passengers' choice of the airport in Kano. Similarly, access time to the airport, frequency of flights at the airport, minimum waiting time and previous usage of the airport are the factors that explains the choice of the airport by sampled passengers.

Indeed, the location of an airport within a region is an important usage consideration. Airports are spatial nodes that users consider especially with regards to its accessibility. The accessibility of an airport within a region is vital especially if the airport is easily accessible from the locations of prospective users. MAKIA is located in the central part of northern Nigeria with a viable catchment area encompassing most major urban centers like Kaduna, Sokoto, Maiduguri, Zaria, Bauchi, Katsina just to mention a few. Passengers who wish to embark on international trips may have to use MAKIA which is the nearest international airport. However, with the emergence of an international airport in Abuja, the Federal Capital Territory, the two airports now act as intervening opportunity to one another.

It is apparent that the location of the airport (0.66) and access time to the airport (0.60) stands out as the most important factors that load on factors one and two (Table 4). Passengers more often consider the access time they spend to reach an airport. Specifically, it has been argued in a study in Norway that improved road infrastructure contribute to higher levels of air traffic leakage from geographical catchment areas of a regional airport to some other airports (Gjerdaker et al., 2008). According to Proussaloglou and Koppelman (1999) the individual traveler is a rational decision maker who actively searches for options, and selects the option with the highest overall utility that satisfies his or her individual expectation. The findings of this study are similar to the findings of Ishii et al. (2009) as well as the works of Hess and Polak (2005) which identified access time as a statistically significant airport choice factor.

Similarly, the choice process is viewed as an iterative process of acquiring and evaluating 
Table 4

Rotated Factor Matrix of the Airport Choice Factors

\begin{tabular}{|c|c|c|c|}
\hline \multirow[t]{2}{*}{ Airport Choice Factors } & \multicolumn{3}{|c|}{ Factor } \\
\hline & 1 & 2 & 3 \\
\hline Available parking space at the airport & 0.776 & & \\
\hline The nature of airport services available & 0.742 & & \\
\hline Location of the airport in the region & 0.660 & 0.522 & \\
\hline Access time to airport & 0.606 & 0.562 & \\
\hline Frequency of flight at the airport & 0.594 & 0.402 & \\
\hline Minimum waiting time at airport & 0.445 & 0.845 & \\
\hline Previous usage of the airport & 0.447 & 0.834 & \\
\hline Low fare charges & & & 0.739 \\
\hline Connective capacity of flights from the airport & & & 0.573 \\
\hline Availability of aircraft & & 0.432 & 0.482 \\
\hline
\end{tabular}

Extraction Method: Principal Axis Factorin;

Rotation Method: Varimax with Kaiser Normalization

Source: Author's computation

information about air travel alternatives. The results as presented in Table 4 equally depicts that the frequency of flights at MAKIA is the third pertinent variable that explains the choice of the airport by passengers on international travels. The airport is the main airport serving the northern region of Nigeria especially for international traveling. Several airlines fly scheduled flights to and from the airport on regular basis. The airport has flight connections with different countries in Africa, Middle East and Europe. For this reason therefore, the frequency of flights at the airport invariably affects passengers' choice of the airport for their scheduled international journeys. The familiarity of passengers with an airport is the fourth critical factor that users consider in their choice behaviour for the airport of their arrival and departure point. The previous usage of an airport inadvertently influence choice behaviour of users of the airport surveyed. Minimum waiting time at the airport is the fifth factor that explains traveler's choice of the airport. This finding is similar to the observation made by Zhang and Xie (2005) that the experience and knowledge of a passenger about a local airport has strong effect on airport choice. It is not surprising however, that this was considered the fourth and fifth explanatory choice factors of the MAKIA passengers sampled.

Pertinently however, airport choice factors are by nature not independent of one another, but depend to some extent by the degree of association which users attach to them. Consequently, there is the need to determine the nature of the relationship. Further examination of the analysis of choice factors under investigation reveals the nature and magnitude of their association. Table 5 shows the correlation matrix of the ten choice factors considered in the study. The variables are denoted as $\mathrm{X}_{1}$ (available parking space at the airport), $X_{2}$ (the type of airport services offered at the airport), $\mathrm{X}_{3}$ (the location of the airport in the region), $\mathrm{X}_{4}$ (access time to reach the airport), $X_{5}$ (frequency of scheduled 
flights at the airport), $\mathrm{X}_{6}$ (minimum waiting time at the airport), $\mathrm{X}_{7}$ (previous usage of the airport), $\mathrm{X}_{8}$ (low airport charges), $\mathrm{X}_{9}$ (the connective capacity of the airport) and $\mathrm{X}_{10}$ (availability of aircraft). In fact, the result presented in Table 5 shows that the association of the variables are all positively related.

It is apparent that the strongest positive correlation between the pairs of the variables under investigation is between previous usage of the airport and minimum waiting time at the airport, $r=0.982, p<0.001$. The implication of this result is that the more familiar passengers are with the airport, the more knowledge they have of the average minimum waiting time at the airport. This is expected because respondents' familiarity or previous knowledge of an airport, no doubt, determines a passengers' choice behaviour. Similarly, the correlation between access time taken to reach the airport and the location of the airport shows very strong positive correlation $(r=0.970, p<0.001)$. Indeed, this association is instructive because the greater a passenger using an airport considers accessibility of the airport; the more likelihood will be the consideration of the location of the airport within the region. Air travelers also consider the access time to and from the airport from the standpoint of their previous knowledge of the distance of the airport from their residences. This reason perhaps, may have accounted for the positive relationship $(r=0.780, p<0.001)$ between the pair of access time to the airport and previous usage of the airport. It is important to note that these correlations provide essential integrity checks on the passengers' responses of the variables under investigation.

The results as presented so far indicate that the ten variables under investigation are important passenger choice behavioural factors. This is because the ability of an airport to attract a passenger depends to a large extent on the attributes to which prospective passengers attach to an airport. This is coupled with the perception of the airport user with regards to certain information at his disposal that could translate to actual choice behaviour. The choice of an airport among competing airports presents travelers with multi-dimensional choice context that can be resolved by careful

Table 5

Correlation Matrix of the Choice Factors

\begin{tabular}{|c|c|c|c|c|c|c|c|c|c|c|}
\hline & $\mathbf{X 1}$ & $\mathbf{X} 2$ & $\mathbf{X} 3$ & X4 & X5 & X6 & $\mathbf{X} 7$ & X8 & X9 & X10 \\
\hline X1 & 1.000 & & & & & & & & & \\
\hline X2 & 0.433 & 1.000 & & & & & & & & \\
\hline X3 & 0.545 & 0.335 & 1.000 & & & & & & & \\
\hline X4 & 0.449 & 0.278 & 0.780 & 1.000 & & & & & & \\
\hline X5 & 0.522 & 0.325 & 0.970 & 0.748 & 1.000 & & & & & \\
\hline X6 & 0.457 & 0.268 & 0.757 & 0.982 & 0.750 & 1.000 & & & & \\
\hline $\mathbf{X} 7$ & 0.393 & 0.294 & 0.673 & 0.688 & 0.692 & 0.691 & 1.000 & & & \\
\hline X8 & 0.262 & 0.474 & 0.442 & 0.340 & 0.439 & 0.325 & 0.520 & 1.000 & & \\
\hline X9 & 0.199 & 0.092 & 0.629 & 0.585 & 0.672 & 0.595 & 0.588 & 0.298 & 1.000 & \\
\hline $\mathbf{X 1 0}$ & 0.224 & 0.158 & 0.624 & 0.578 & 0.658 & 0.578 & 0.581 & 0.371 & 0.665 & 1.000 \\
\hline
\end{tabular}

Source: Author's computation 
analysis of the attributes of competing airports. Travelers, indeed seek to maximize their travel utility by choosing the airport with the best utility.

\section{Policy Implications}

The ability of an airport to attract passengers can be explained partly by geography (location and relative accessibility of the airport) and partly by other variables that are service oriented in nature. Airports spatially compete so that resources tend to cluster in most perceived lucrative markets. It is quite obvious that airports vary in their attributes especially with regards to local geographical conditions and levels of access time. It is therefore important that airport managers and planners should take into cognizance the attributes that act as determinants of choice behaviour. Specifically, efforts should be made to make regional airports relatively accessible to different passengers. For an airport to be competitive, it must have good transport network linking it so that prospective travelers can easily access the airport. Strictly speaking, not all passengers are willing to travel longer distances to access an airport. Indeed, some studies have shown that leisure travelers are more willing to travel almost 2 hours longer than business travelers in order to use an alternative airport with cheaper flight tickets and convenient flights (Lian and Ronnevik, 2011). As a consequence, in spite of an airport being close to a passenger, some travelers may opt for other airports that are naturally far from the passenger. This results in what may be termed traffic leakage.

Airport operators generally must strive to make airports very competitive. This is because travelers often make their travel decisions based on some attributes most of which this study has considered. The competitiveness of an airport depends on passengers' perception of the service quality of an airport. An airport with more frequent flight schedule is, all things being equal, more likely to attract passengers than an airport with less frequent flight schedules. Regular schedules of flights are indicators of airport reliability. The regularity of flights invariably reposes confidence and trust which traveler's uses as a yardstick of measuring the reliability of an airport. The quality of service provided at an airport over time creates a formidable impression which determines traveler's choice of an airport for departure or arrival. This impression, $a b$ initio, is developed through passengers' previous knowledge of the airport.

\section{Conclusion}

Many factors affect an airport's ability to attract travelers, including the location of the airport, the nature of access time to the airport, the nature of airport service quality, airport infrastructural capacity and activities, minimum waiting time at the airport, low fare charges, travelers' previous knowledge of the airport and airports connective capacity. Based on a vibrant data set obtained from 240 international passengers sampled at MAKIA, this paper applies factor analysis to identify the critical factors that best explains traveler's choice of the airport for their arrival and departures. The analysis relied on eigenvalues to reduce the considered variables into few orthogonal variables that were used to explain the passenger's choice decisions. The results indicate that the choice of the airport by travelers is based on five critical factors: airport location, access time to the airport, flight frequency, traveler's previous usage of the airport and minimum waiting time at the airport in that order. These results suggest that passengers as rational beings patronize the airport based on these critical factors. 
By implication, there is the need for airports to invest in infrastructural development among which is accessibility to the airport. Furthermore, airports as competitive spatial nodes must endeavour to maintain some level of reliability with regards to flight frequency and service delivery. In summary, the ability of MAKIA to attract passenger traffic in a multi-airport region like Nigeria is a function of characteristics and service quality. This in essence is crucial to the establishment of the airport as a regional hub with a viable catchment market area.

\section{References}

Ashford, N.; Bencheman, M. 1987. Passengers' choice of airport: an application of the multinomial logit model, Transportation Research Record, 1147: 1-5.

Basar, G.; Bhat, C. 2004. A parameterized consideration set model for airport choice: an application to the San Francisco Bay area, Transportation Research Part B: Methodological. DOI: http://dx.doi.org/10.1016/j. trb.2004.01.001, 38(10): 889-904.

Caves, R. 1996. Multinational Enterprise and Economic Analysis. Cambridge: Cambridge University Press.

Fuellhart, K. 2007. Airport catchment and leakage in a multi-airport region: the case of Harrisburg International, Journal of Transport Geography. DOI: http://dx.doi. org/10.1016/j.jtrangeo.2006.08.001, 15(4): 231-244.

Gjerdaker, A.; Ronnevik, J.; Lian, J.I. 2008. The road to Lofoten: Effects on business, tourism and aviation. Institute of Transport Economics, Oslo: Report 994.

Harvey, G. 1987. Airport choice in a multiple airport region, Transportation Research Part A: General. DOI: http://dx.doi. org/10.1016/0191-2607(87)90033-1, 21(6): 439-449.

Hess, S.; Polak, J.W. 2005. Mixed logit modeling of airport choice in multi-airport regions, Journal of Air
Transport Management. DOI: http://dx.doi.org/10.1016/j. jairtraman.2004.09.001, 11(2): 59-68.

Hess, S.; Polak, J.W. 2006. Exploring the potential for crossnesting structures in airport choice analysis: a case study of the Greater London area, Transportation Research Part E: Logistics and Transportation Review. DOI: http://dx.doi. org/10.1016/j.tre.2005.09.001, 42(2): 63-81.

Ishii, J.; Sunyuoug, J.; Van Dender, K. 2009. Air travel choices in multi-airport markets, Journal of Urban Economics. DOI: http://dx.doi.org/10.1016/j.jue.2008.12.001, 65(2): 216-227.

Kanafani, A.; Young, H.S. 1977. An investigation of short haul air transportation in southern United States. Technical Report Server, NASA-CR 152166.

Landau, S.; Everitt, S.B. 2004. A Handbook of Statistical Analyses Using SPSS. London: Chapman and Hall/CRC Press Company. 336 p.

Lian, I.J.; Ronnevik, J. 2011. Airport competitionregional airport losing ground to main airports, Journal of Transport Geography. DOI: http://dx.doi.org/10.1016/j. jtrangeo.2009.12.004, 19(1): 85-92.

Malhotra, N.K.; Hall, J.; Shaw, M.; Crisp, M. 1996. Marketing Research: An Applied Orientation. PrenticeHall: Sydney.

Nigerian Airspace Management Agency (NAMA). 2010. Annual News Bulletin. A Publication of Nigerian Airspace Management Agency, Abuja: Nigeria. 25 p.

Nigerian Civil Aviation Authority (NCAA). 2003. Nigerian Aviation Today, Annual News Letter Aviation Watch, 2(4): 21-30.

Ohashi, H.; Kim, T.; Oum, T.H.; Yu, C. 2005. Choice of air cargo transshipment airport: an application to air cargo traffic to/from Northeast Asia, Journal of Air Transport Management, 11(3): 149-159.

\section{jitte 241}


Oum, T.H.; Park, J.H. 2004. Multinational firm's location preference for regional distribution centers: focus on the northeast Asian region, Transportation Research Part E: Logistics and Transportation Review. DOI: http://dx.doi. org/10.1016/S1366-5545(03)00036-X, 40(2): 101-121.

Ozoka, I.A. 2009. Aviation Systems Planning and Operations: Blending Theory with Professional Practice. Zaria: Ahmadu Bello University Press Limited. 89 p.

Park, J.; Robertson, R.; Wu, C. 2004. The effect of airline service quality on passengers' bahavioural intentions: a Korean case study, Journal of Air Transport Management. DOI: http://dx.doi.org/10.1016/j.jairtraman.2004.06.001, 10(6): 435-439.

Pels, E.; Nijkamp, P.; Rietveld, P. 2003. Access to and competition between airports: a case study for the San Francisco Bay area, Transportation Research Part A: Policy and Practice. DOI: http://dx.doi.org/10.1016/S09658564(02)00007-1, 37(1): 71-83.

Proussaloglou, K.; Koppelman, F.S. 1999. The choice of air carrier, flight and fare Class, Journal of Air Transport Management. DOI: http://dx.doi.org/10.1016/S09696997(99)00013-7, 5(4): 193-201.

Thompson, A.; Caves, R. 1993. The projected market share for a new small airport in south of England, Regional Studies, 27(2): 137-147.

Windle, R.; Dresner, M. 1995. Airport choice in a multiairport region, Journal of Transportation Engineering, 121(4): 332-337.

Zhang, Y.; Xie, Y. 2005. Small community airport choice behaviour analysis: a case study of GTR, Journal of Air Transport Management. DOI: http://dx.doi.org/10.1016/j. jairtraman.2005.07.008, 11(6): 442-447. 